\title{
Rabies and Wildlife
}

\section{By Michael Woodford, M.R.C.V.S}

Rabies in human beings is always fatal. The commonest source of human infection is the domestic dog, which in turn is infected by wild carnivorous animals. As a result of the widespread outbreak of rabies in recent years in Europe, Asia, Africa and the Americas there have been demands for wholesale slaughter of certain wild animals. The recently published fifth report of the World Health Organisation (WHO) Expert Committee on Rabies* recommends control of certain vector species. The danger, as Michael Woodford points out in this assessment of the report, is that the methods used will almost certainly involve the killing of other harmless wildlife. $\mathrm{N}$ recent years there has been a widespread outbreak of rabies in
wildlife in Europe, Asia, Africa and North and South America. The domestic or semi-domestic dog is the commonest source of human infection, but the dog is infected by a variety of wild animals: in Europe, mainly the fox; in Asia and Asia Minor often the wolf and the jackal, and in Africa mongooses and weasels; in North America foxes, coyotes and skunks are the main reservoirs of infection; in Canada rabies is considered to be a factor controlling the Arctic fox.

In Latin America vampire bats present a unique problem. The infected bat usually dies of the rabies infection, but there is experimental evidence to show that some bats become symptomless carriers and can transmit the disease for several months. Rabies in insectivorous bats was first reported in the USA in 1953; later reponts have shown that infection of these bats is widespread throughout the whole of North America. There have been five cases of bat-transmitted rabies in man in the USA but, in contrast to vampire-bat rabies in Latin America, there are no records of insectivorous bats transmitting the disease to terrestrial mammals by biting except to man. Two persons are reported to have developed rabies, without known exposure to biting bats, after entering a cave in which millions of insectivorous bats roosted by day ${ }^{1}$, and foxes and coyotes held in bat- and arthropodproof cages in the same cave also contracted the disease ${ }^{2}$. The inference is that both men and animals acquired the disease by inhaling virus particles suspended in an atmosphere heavily polluted with bat faeces and urine. However the WHO Report emphasises that these observations were made only in the bat caves of the south-western USA where vast numbers of infected bats have been found; there is no reason to believe that this phenomenon is likely to occur outside such cave environments. A few cases of bat rabies have been reported in Yugoslavia and Turkey, and one human rabies death has been attributed to bat exposure in India. But if the carriage of rabies by insectivorous bats is a new biological phenomenon it may tend to spread northwards as it has done in North America. The English

* WHO, Geneva, Switzerland, 5s. Sw. Fr. 3. 
Channel may then prove to be no barrier against infection, for as recently as 1956 a colony of mouse-eared bats Myotis myotis, a very rare species in Britain but common on the Continent, and one which is known to travel up to $260 \mathrm{~km}^{3}$, was discovered in Dorset 4 .

It is characteristic of some of the wild carnivores involved in the spread of rabies that their populations undergo cyclical changes. These fluctations are usually linked to similar cyclical changes in the numbers of the small rodents upon which they are accustomed to feed. Thus a vole plague in eastern Europe is often followed by a rapid increase in the population of foxes. Rabies, too, tends to recur in certain well defined areas where the wildlife vector species has undergone a cyclic population increase. The epidemic rabies of foxes and wolves in the Arctic often follows a lemming irruption, but so far the virus of rabies has not been isolated from the salivary glands of the lemmings. In those parts of the USA where the wild population is substantially controlled by endemic mange infection there is no rabies problem. It is reasonable to assume, therefore, that the increase in morbidity among carnivores is a measure of the population density. The WHO Report recognises this and advocates a programme of population reduction of proved vector species as being the only available method of wildlife rabies control.

As rabies in human beings is always fatal, conservationists cannot possibly oppose this method of attacking it, but they do urge that the control methods used should be as specific as possible. The Expert Committee is concerned with the safety aspect from the human point of view only but gives no consideration at all to the danger for other wildlife. As no member of the Committee represents wildlife interests this is not surprising, but it should be remedied. The control methods advocated by the Committee-trapping, gassing, poisoning and shooting-are likely in the main to be non-specific, and the recommendation that all control work should be directed by professionally trained predator control specialists does not give much comfort to the conservationist in view of the history of predator control in many countries, and in the absence of any instructions urging specificity from the wildlife point of view.

The best hope of achieving a fully specific method of control is that current research will produce a feasible means of interrupting the reproductive cycle of certain wild carnivores. This would make it possible to control population densities at a level that would not support a rabies epidemic, and do away with all hit and miss methods. This article is based on an assessment of the WHO Report by the author

\section{REFERENCES} published in "The Veterinary Record".

1. IRONS, J. V., EADS, R. B., GRIMES, J. E., CONKLIN, A., Tex. Rep. Biol. Med. 1957, 15, 292.

2. CONSTANTINE, D. G., US Publ. Hith. Rep., 1962, 77, 287.

3. EISENTRAUT, M., Zbl. Kleintierk, 1937, 13, 1-184.

4. BLACKMORE, M., Proc. Zool. Soc., Lond., 127, 201-3. 


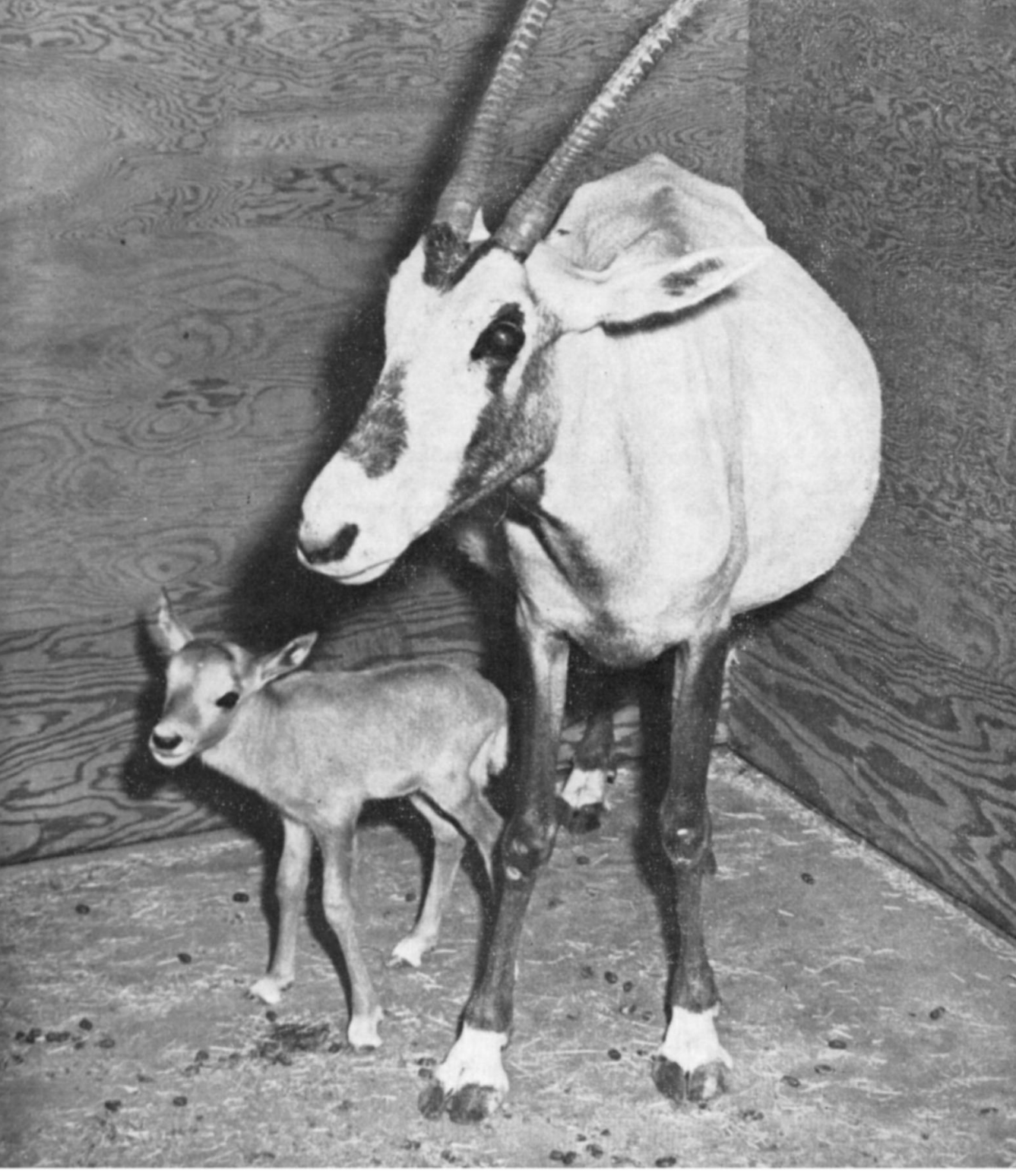

\section{MOTHER AND DAUGHTER}




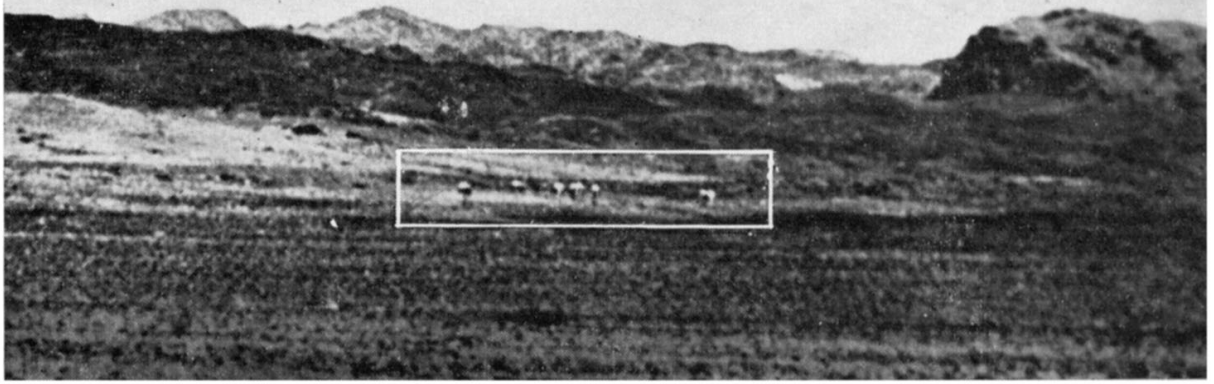

Plate 2. WILD HORSES. Dr Kaszab's photograph taken last summer of the Przewalski horses, seven mares and one stallion (the animal on the right), galloping away from his party on the barren, 6,800-ft.-high plateau of the Takhiin Shar nuruu in western Mongolia.

\section{WILD HORSES IN MONGOLIA}

Plate 3. Map of the area in which the horses were seen.

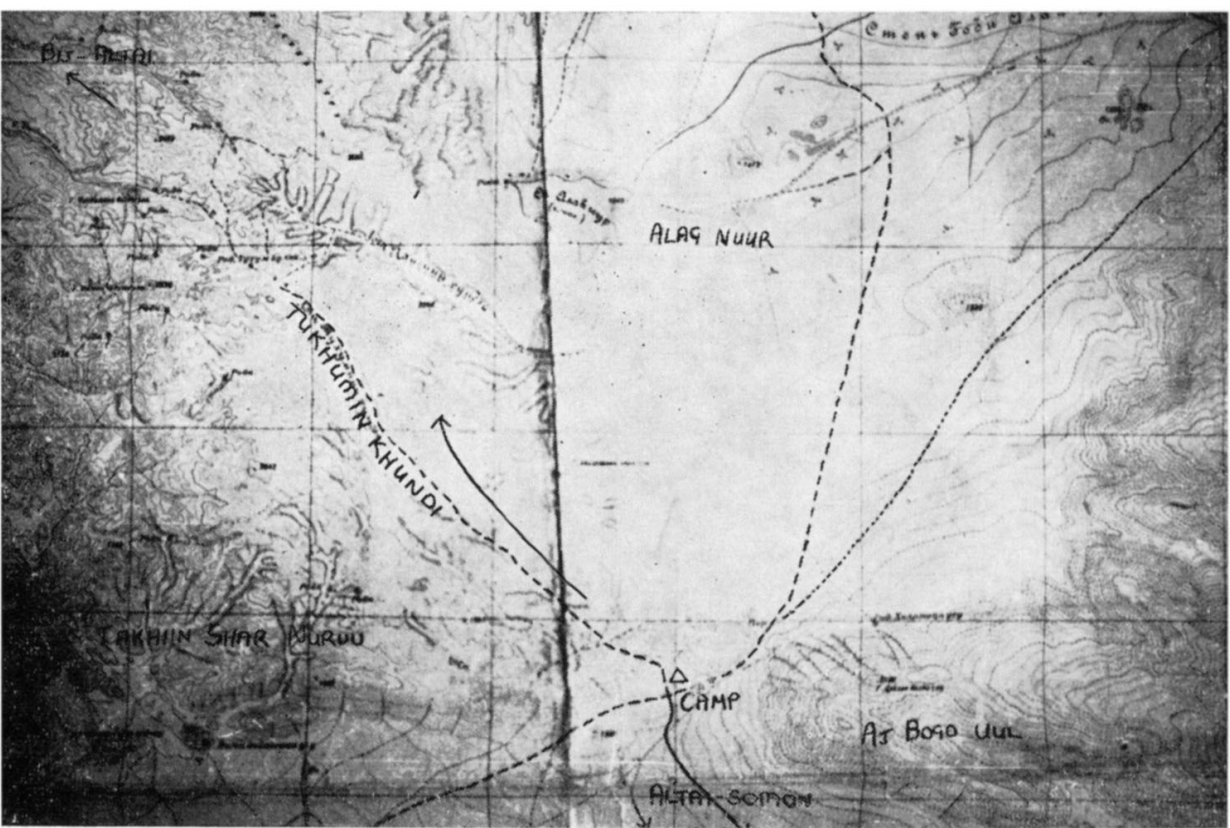

